\title{
Transglutaminase-1 Mutations in Omani Families with Lamellar Ichthyosis
}

\author{
Aisha Al-Naamani ${ }^{a} \quad$ Ahmed Al-Wailyc Mohammed Al-Kindi ${ }^{\mathrm{b}}$ Maha Al-Awadi ${ }^{\mathrm{a}}$ \\ Said Ali Al-Yahyaee ${ }^{a}$ \\ Departments of ${ }^{a}$ Genetics, ${ }^{b}$ Biochemistry and ${ }^{\mathrm{c} F a m i l y}$ and Public Health Sultan Qaboos University, Al-Khoud, Oman
}

\section{Key Words}

Scaly skin · Collodion baby · TGM1 - Oman

\begin{abstract}
Objective: To determine the molecular basis of familial ichthyosis in three Omani families. Subjects and Methods: Nine patients from three consanguineous families, $A, B$, and $C$, were born with typical features of lamellar ichthyosis subtype including collodion membrane and maintained ectropion, and epidermal scaling through their childhood. The 4 patients from family $B$ had more severe symptoms requiring neonatal critical care and subsequent regular treatment with emollients, eye lubricants, and low-dose acitretin. DNA was extracted from peripheral blood by standard methods. The samples were initially genotyped to screen known loci linked to recessive ichthyosis on chromosomes 2q33-32 (ABCA12), 14q11 (TGM1), and 19p12-q12 using commercially supplied polymorphic fluorescent microsatellite markers. TGM1 was analyzed by direct sequencing for disease-associated mutations. Results: Two known pathogenic mutations in TGM1 were detected: p.Gly278Arg in families $A$ and $B$ and p.Arg396His in family C. These two mutations were segregating in an autosomal recessive mode of inheritance. Conclusion: Two known pathogenic TGM1 mutations were
\end{abstract}

\begin{tabular}{ll}
\hline KARGER & $\begin{array}{l}\text { ( } 2013 \text { S. Karger AG, Basel } \\
1011-7571 / 13 / 0225-0438 \$ 38.00 / 0\end{array}$ \\
E-Mail karger@karger.com & $\begin{array}{l}\text { This is an Open Access article licensed under the terms of the } \\
\text { www.karger.com/mpp }\end{array}$ \\
$\begin{array}{l}\text { Creative Commons Attribution-NonCommercial } 3.0 \text { Un- } \\
\text { ported license (CC BY-NC) (www.karger.com/OA-license), } \\
\text { applicable to the online version of the article only. Distribu- } \\
\text { tion permitted for non-commercial purposes only. }\end{array}$
\end{tabular}

detected in three large consanguineous Omani families with lamellar ichthyosis. This study confirmed the geographic distribution of known mutations to an apparently unrelated population.

Copyright ๑ 2013 S. Karger AG, Basel

\section{Introduction}

Autosomal recessive congenital ichthyosis (ARCI, MIM 190195) is clinically and genetically a heterogeneous group of dermatological scaly skin disorders. It is classified into three clinical subtypes: lamellar ichthyosis (LI, MIM 242300), congenital ichthyosiform erythroderma (MIM 242100), and harlequin ichthyosis (MIM 242500) [1, 2]. Harlequin ichthyosis is fatal due to severe movement restriction and respiratory distress caused by thick hard cornified skin [1]. Infants affected with LI are born encased in a hyperkeratotic translucent membrane, known as collodion baby, and within 2 weeks develop large, thick, brownish lamellar scales with minimal erythema. Additionally, LI is associated with crumpled ears, alopecia, eclabium, and ectropion. On the other hand, infants affected with congenital ichthyosiform erythroderma develop fine white scales with erythroderma. 
Table 1. Clinical characterization of affected families

\begin{tabular}{|c|c|c|c|}
\hline \multirow[t]{2}{*}{ Feature } & \multicolumn{3}{|l|}{ Family } \\
\hline & A & $\mathrm{B}$ & $\mathrm{C}$ \\
\hline Patients, $\mathrm{n}$ & 3 & 4 & 2 \\
\hline Collodion membrane at birth & + & + & + \\
\hline Ectropion at birth & + & + & + \\
\hline Eclabium at birth & - & + & - \\
\hline Flattening of nose and ears at birth & - & + & - \\
\hline Childhood generalized scaling & mild & fish-like & mild \\
\hline Ectropion and alopecia at the temporal scalp & - & + & - \\
\hline Current treatment & $\begin{array}{l}\text { acitretin } \\
\text { (intermittently) }\end{array}$ & $\begin{array}{l}\text { emollients and eye } \\
\text { lubricants along with low- } \\
\text { dose acitretin (regularly) }\end{array}$ & $\begin{array}{l}\text { acitretin and } \\
\text { emollient } \\
\text { (frequently) }\end{array}$ \\
\hline Severity of the condition & mild & severe & mild \\
\hline
\end{tabular}

The sign + denotes the presence and the sign - denotes the absence.

To date mutations in eight genes have been found in various subtypes of ARCI including: $A B C A 12$ (MIM 607800) [3], NIPAL4 (MIM 609383) [4], TGM1 (MIM 190195) [5], ALOX12B (MIM 603741) [6], ALOXE3 (MIM 607206) [7], CYP4F22 (MIM 611495) [8], PNPLA1 (MIM 612121) [9] and LIPN (613924) [10]. Additional intervals in variants not associated with disease have also been identified [11]. Mutations in the transglutaminase-1 (TGM1) gene on 14q11.2 are the most common cause of ARCI, accounting for over $30 \%$ of the cases from diverse ethnic backgrounds [11-15]. TGM1, also known as keratinocyte transglutaminase, plays a significant role in the maturation of human epidermal cells by the formation of an isodipeptide cross-linking bond, thus assembling a highly insoluble layer known as cornified cell envelope, which in turn obviates excessive water loss and provides a protective shield against an inhospitable environment [16].

No previous study has been done in the Omani population with a birth prevalence of 2 LI cases per 10,000 births [17]. In this study, we describe clinically and genetically 9 patients from three consanguineous Omani families affected with LI.

\section{Subjects and Methods}

\section{Clinical and Laboratory Investigations}

This study was approved by the institutional Ethics Committee. Subjects or their guardians gave informed consent. The patients in the three families A, B, and C (fig. 1) were clinically characterized by a dermatologist (A.W.). The clinical characterization of the three families is summarized in table 1. Family A has 3 affected children. The proband, a 5-year-old male, was born with collodion membrane and mild ectropion. He was immediately started on acitretin for 5 days and his skin improved dramatically and he was discharged from the hospital within 2 weeks. According to the parents, the proband's siblings, a 15-year-old boy and a 13-year-old girl, were born with mild collodion membrane which improved spontaneously. The 3 children are living comfortably and require acitretin intermittently, averaging once every 2 years for 3-6 months when their condition worsens and their skin becomes more thickened and the scales become troublesome.

The 4 affected patients from family B were born with severe features of LI collodion baby, covered with a thick taut skin membrane, ectropion, eclabium, and flattening of nose and ears. These patients were initially kept on intravenous fluids, humidified incubator air, acitretin for 2 weeks and Augmentin antibiotic. After about a month and a half the skin started peeling, and patients were advised to continue with liquid paraffin treatment. Currently they have classic features of LI with brownish fish-like scales on the skin accentuating the flexures, associated with ectropion and alopecia at the temporal scalp. They are on regular emmolients and eye lubricants along with low-dose acitretin (10 $\mathrm{mg}$ on alternate days). It was noted that their condition worsens during the dry and windy winter months necessitating regular treatment.

The 2 affected patients from family $\mathrm{C}$ were known cases of LI from birth, with generalized scaling and ectropion of eyes. Patients are undergoing acitretin, and emollient treatment.

Peripheral venous blood was drawn in EDTA tubes and DNA was extracted using a commercially available kit (QIAGEN Kit), according to the manufacturer's instructions. The samples were initially genotyped to screen known loci linked to recessive ichthyosis on chromosomes 2q33-32 (ABCA12), 14q11 (TGM1), and $19 \mathrm{p} 12-\mathrm{q} 12$ using commercially supplied polymorphic fluorescent microsatellite markers (ABI PRISM ${ }^{\circledR}$ Linkage Mapping Sets, Linkage Mapping Set-HD5, MD10, and LD20). A total of 10 markers were used (D2S2321, D2S2361, D2S163, D14S283, D14S972, 


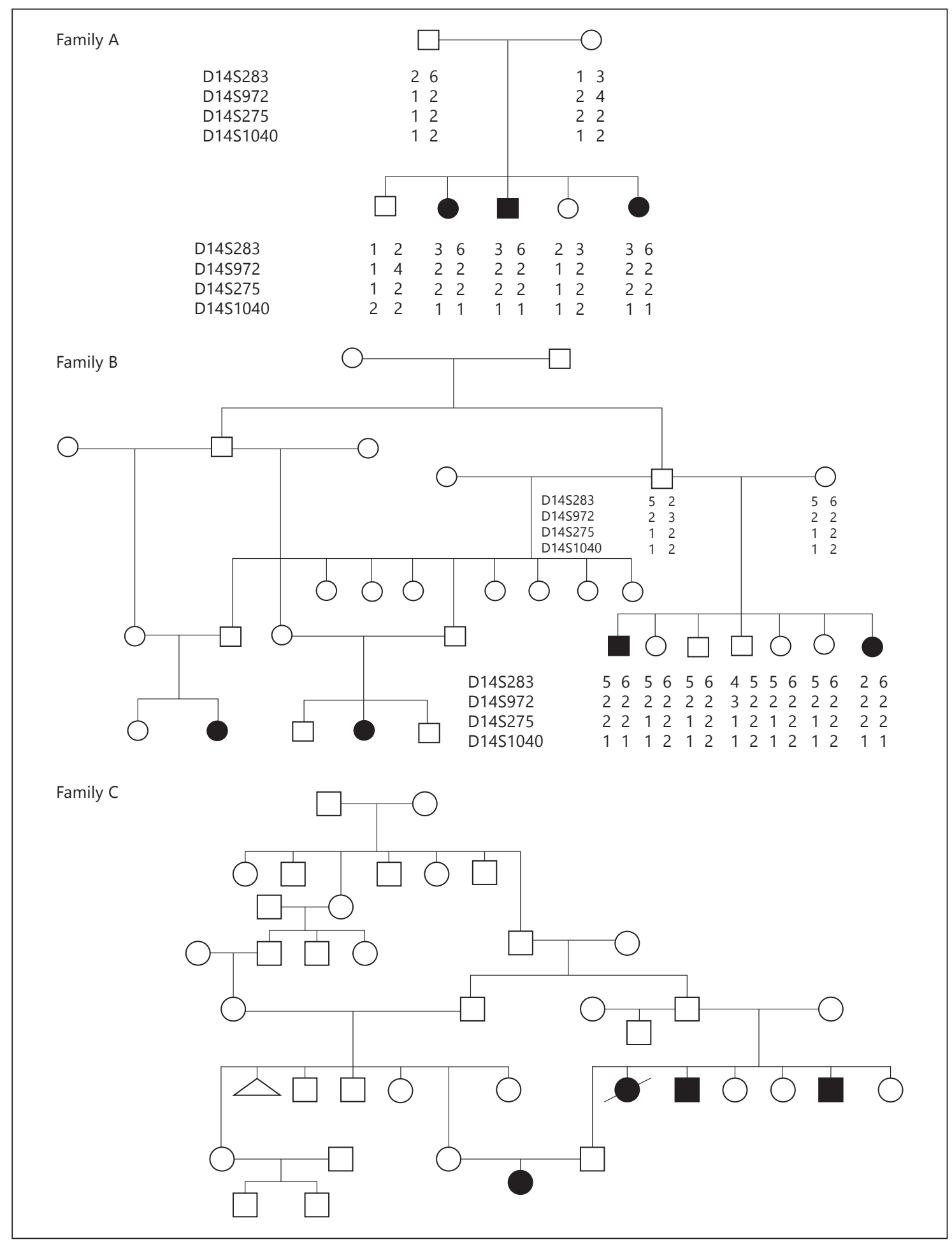

Fig. 1. Family pedigrees (A, B, C) affected with LI. The haplotypes of markers spanning D14S972 to D14S1040 show the homozygous region shared by the affected subjects in families A and B. Pedigree symbols: $\square=$ male, $\mathrm{O}$ = female; a diagonal line designates deceased, and filled boxes or circles designate affected. 
Fig. 2. DNA sequences of TGM1 showing c. $832 \mathrm{G}>\mathrm{A}$ mutation in exon 5 detected in families A and B (a), c.1187G $>$ A mutation in exon 8 detected in family $\mathrm{C}$ (b) and ethidium bromide-stained $10 \%$ polyacrylamide gel electrophoresis of NlaIV restriction digestion at the $c .832 \mathrm{G}>\mathrm{A}$ mutation site where G-to-A substitution eliminated NlaIV site in the 317-bp fragment (c). A = Affected; $\mathrm{C}=$ carrier; $\mathrm{N}=$ normal.

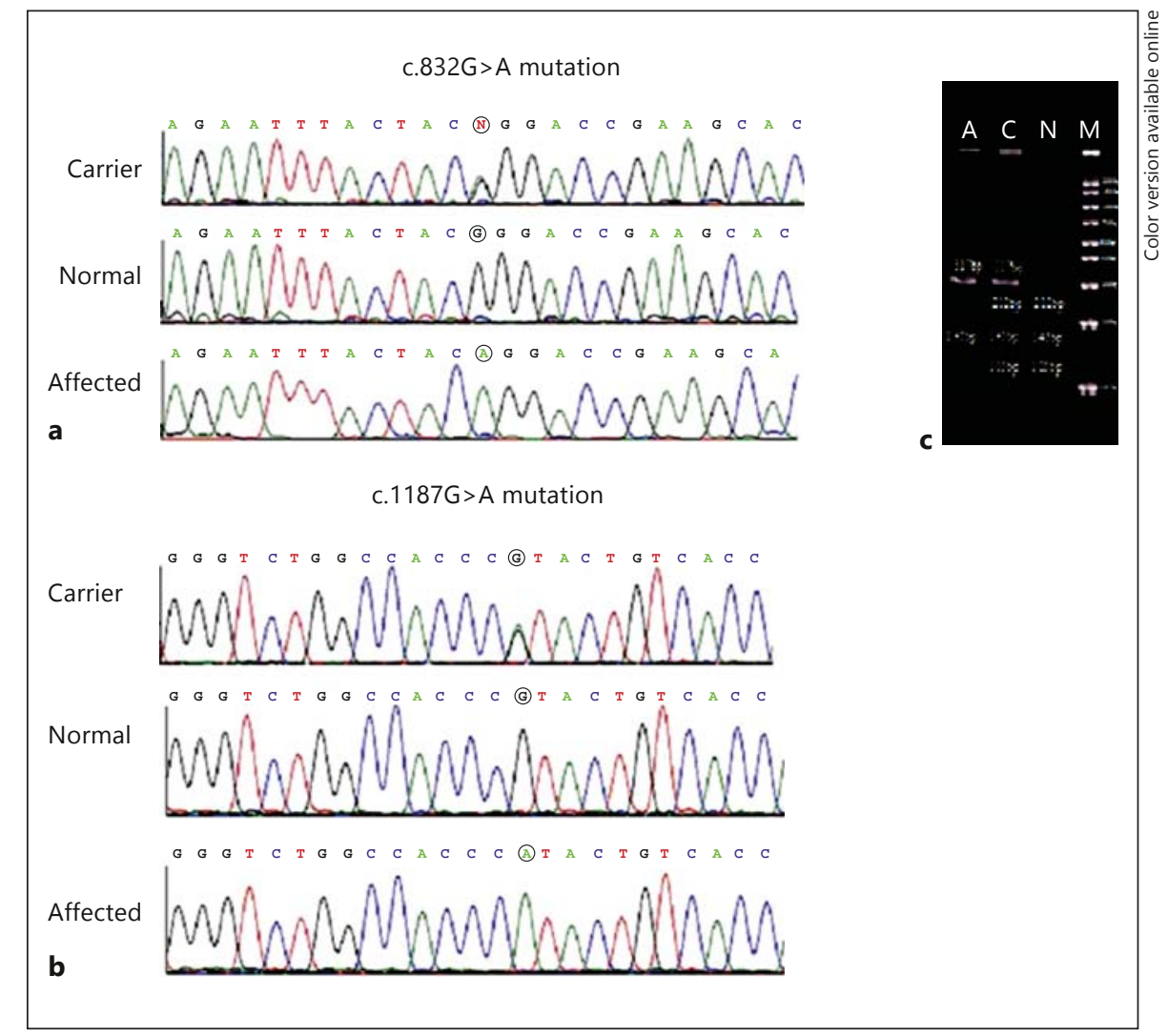

D14S275, D14S1040, D19S221, D19S226 and D19S566). DNA was amplified in $15 \mu \mathrm{l}$ reaction volume containing $20 \mathrm{ng}$ of genomic DNA, $9 \mu \mathrm{l}$ True Allele ${ }^{\mathrm{TM}}$ PCR Premix (Part No. 403062), and $1 \mu \mathrm{l}$ of primer mix ( $5 \mu \mathrm{M}$ each primer). The thermocycling condition included an initial denaturation step at $95^{\circ} \mathrm{C}$ for $12 \mathrm{~min}$ followed by a first round of $10 \mathrm{cycles}$ at $94^{\circ} \mathrm{C}$ for $15 \mathrm{~s}, 55^{\circ} \mathrm{C}$ for $15 \mathrm{~s}$ and $72^{\circ} \mathrm{C}$ for $30 \mathrm{~s}$. The second round of amplification was performed for 20 cycles at $89^{\circ} \mathrm{C}$ for $15 \mathrm{~s}, 55^{\circ} \mathrm{C}$ for $15 \mathrm{~s}$ and $72^{\circ} \mathrm{C}$ for $30 \mathrm{~s}$, followed by final extension for $10 \mathrm{~min}$ at $72^{\circ} \mathrm{C}$. PCR products of different labels and sizes were pooled together prior to analysis using the 310 ABI Genetic Analyzer. Once the locus was identified, the TGM1 gene (NM_000359) was sequenced with intronic primers (available upon request) which were designed using Exon Primer Design with Primer 3 (http://129.43.22.27/ primer/EasyExonPrimer. html): $15 \mu$ reaction volume containing $20 \mathrm{ng}$ of genomic DNA, $0.2 \mathrm{mM}$ dNTP mix, $0.2 \mu \mathrm{M}$ of each primer, $1.5 \mathrm{mM} \mathrm{MgCl}_{2}$ and 0.025 units $/ \mu$ l AmpliTaq Gold. The thermocycling condition included an initial denaturation at $94^{\circ} \mathrm{C}$ for $12 \mathrm{~min}$, followed by 40 cycles of amplification at $94^{\circ} \mathrm{C}$ for $30 \mathrm{~s}, 57^{\circ} \mathrm{C}$ (exon 5) and $60^{\circ} \mathrm{C}$ (exon 8) for $30 \mathrm{~s}$ and $72^{\circ} \mathrm{C}$ for $30 \mathrm{~s}$ and contained a final extension step at $72^{\circ} \mathrm{C}$ for $10 \mathrm{~min}$. Sequencing reaction was performed using the Big Dye Terminator method (part No. 4336917), which was then analyzed on an ABI PRISM 3130xl Genetics Analyzer. Sequence analysis was performed using DNASTAR Lasergene, version 7 (Madison, Wisc., USA). To confirm the mutation in TGM1, PCR products were digested by NlaIV restriction enzyme for $2 \mathrm{~h}$ and a half at $37^{\circ} \mathrm{C}$, and the digested products were analyzed using a $10 \%$ polyacrylamide gel. Following the identification of the mutations, 100 individuals from the same population were sequenced to determine the frequency of the detected mutations in the general population.

\section{Results}

Homozygosity mapping for known loci linked to LI excluding 2q33-32 and 19p12-q12 showed a common haplotype in the affected families A and B for D14S972, D14S275 and D14S1040, thus suggesting the involvement of the 14q11 locus (fig. 1, family A, family B) in the pathogenesis of LI. Mutational analysis of TGM1 detected a homozygous c.832G $>$ A mutation (NM_000359.2) in exon 5 in affected individuals of families $\mathrm{A}$ and $\mathrm{B}$, while parents of both families were found to be heterozygous for the same mutation (fig. 2a). This substitution replaces the glycine residue at position 278 with an arginine residue, p.Gly278Arg (NP_000350). Affected members of family $\mathrm{C}$ had a homozygous c.1187G $>\mathrm{A}$ mutation in exon 8 of TGM1 (fig. 2b), resulting in a substitution of arginine for histidine at position 396: p.Arg396His. Further analysis 
of other family members confirmed autosomal segregations of the two mutations in the corresponding families. The presence of the c.G596A mutation was confirmed using NlaIV restriction mapping as shown in figure 2c. Neither of these two mutations were detected in $100 \mathrm{control}$ samples from the same population.

\section{Discussion}

In this study, the affected individuals were born with collodion membrane and maintained ectropion, and epidermal scaling through their childhood. These findings are typical features of LI subtype [2].

ARCI can be caused by mutations in many genes. In a large cohort of 520 ACRI families, it was found that $32 \%$ of the patients had mutations in TGM1,16\% in ichthyin, $12 \%$ in $A L O X 12 B, 8 \%$ in CYP4F $22,5 \%$ each in ALOXE3 and $A B C A 12$, and at least $22 \%$ of these cases did not exhibit mutations in any of the known ARCI genes, implying the existence of further loci [11]. Additionally, mutations in PNPLA1 and LIPN were recently identified in ARCI patients $[9,10]$. Simple haplotype analysis using microsatellite markers linked to known loci in families of Arab origin $[12,18-20]$ showed a shared homozygous region between markers D14S972 and D14S275 where TGM1 is located, demonstrating the usefulness of using homozygosity mapping for the identification of ARCI candidate genes in consanguineous families [21], as in this study.

Mutation analysis of TGM1 detected p.Gly278Arg mutation in the two families A and B, indicating a common founder for the two apparently unrelated families who came from the same geographic region. Previously this mutation was found to be inherited in a compound heterozygous with p.Arg286Gln in American LI patients [22] and with p.Asp490Arg in a Kosovo family of Albanian origin with self-healing collodion baby [23]. Biochemical assay of the TGase1 p.Gly278Arg mutant found a significant loss of activity [23]. Molecular modeling predicted that the bulky side chain of the mutant arginine disturbed the linkage between the two $\beta$ barrel domains at the interface of the catalytic core domain where the Gly278 resides [23]. Gly278 was found to be highly conserved among human TGase family enzymes, suggesting a conserved function [16].

The TGM1 p.Arg396His mutation identified in family $\mathrm{C}$ was previously found to cause dramatic loss of TGase 1 activity [24]. The Arg396 was also found in LI patients to be mutated to serine (p.Arg396Ser) [21] and leucine (p. Arg396Leu) [25]. The substitution of Arg396 for His396 at catalytic site core domain of TGase1 was shown by molecular modeling to create surface polarity without changing the structure [24].

To date over 130 TGM1 mutations were found in patients from diverse ethnic backgrounds [11-15]. The detection of p.Gly278Arg and Arg396His, known mutations in our highly inbred and relatively isolated population [26], expands the range of TGM1 mutations to another ethnic group and suggests an independent founder effect from that of Caucasian populations, where these two mutations were previously found.

\section{Conclusion}

Two known pathogenic TGM1 mutations were detected in three large consanguineous Omani families with LI. This study confirmed the geographic distribution of known mutations to an apparently unrelated population.

\section{References}

1 Akiyama M: Harlequin ichthyosis and other autosomal recessive congenital ichthyoses: the underlying genetic defects and pathomechanisms. J Dermatol Sci 2006;42:83-89.

2 Oji V, Tadini G, Akiyama M, et al: Revised nomenclature and classification of inherited ichthyoses: results of the First Ichthyosis Consensus Conference in Sorèze 2009. J Am Acad Dermatol 2010;63:607-641.

-3 Lefèvre C, Audebert S, Jobard F, et al: Mutations in the transporter $A B C A 12$ are associated with lamellar ichthyosis type 2 . Hum Mol Genet 2003;12:2369-2378.
4 Lefèvre C, Bouadjar B, Karaduman A, et al: Mutations in ichthyin, a new gene on chromosome $5 \mathrm{q} 33$ in a new form of autosomal recessive congenital ichthyosis. Hum Mol Genet 2004;13:2473-2482.

5 Russell LJ, DiGiovanna JJ, Rogers GR, et al: Mutations in the gene for transglutaminase 1 in autosomal recessive lamellar ichthyosis. Nat Genet 1995;9:279-283.

6 Lesueur F, Bouadjar B, Lefèvre C, et al: Novel mutations in $A L O X 12 B$ in patients with autosomal recessive congenital ichthyosis and evidence for genetic heterogeneity on chromosome 17p13. J Invest Dermatol 2007;127:829-834.
7 Jobard F, Lefèvre C, Karaduman A, et al: Lipoxygenase-3 (ALOXE3) and 12(R)-lipoxygenase $(A L O X 12 B)$ are mutated in non-bullous congenital ichthyosiform erythroderma (NCIE) linked to chromosome 17p13.1. Hum Mol Genet 2002;11:107-113.

8 Lefèvre C, Bouadjar B, Ferrand V, et al: Mutations in a new cytochrome $\mathrm{P} 450$ gene in lamellar ichthyosis type 3. Hum Mol Gene 2006;15:767-776.

-9 Grall A, Guaguère E, Planchais $S$, et al: PNPLA1 mutations cause autosomal recessive congenital ichthyosis in golden retriever dogs and humans. Nat Genet 2012;44:140-147.
Al-Naamani/Al-Waily/Al-Kindi/

Al-Awadi/Al-Yahyaee 
10 Israeli S, Khamaysi Z, Fuchs-Telem D, et al: Mutation in LIPN, encoding epidermal lipase $\mathrm{N}$, causes a late-onset form of autosomal-recessive congenital ichthyosis. Am J Hum Genet 2011;88:482-487.

11 Fischer J: Autosomal recessive congenital ichthyosis. J Invest Dermatol 2009;129:13191321.

$\checkmark 12$ Herman ML, Farasat S, Steinbach PJ, et al: Transglutaminase-1 gene mutations in autosomal recessive congenital ichthyosis: summary of mutations (including 23 novel) and modeling of TGase-1. Hum Mutat 2009;30: 537-547.

13 Rodríguez-Pazos L, Ginarte M, Fachal L, et al: Analysis of TGM1, ALOX12B, ALOXE3, NIPAL4 and CYP4F22 in autosomal recessive congenital ichthyosis from Galicia (NW Spain): evidence of founder effects. Br J Dermatol 2011;165:906-911.

14 Fachal L, Rodríguez-Pazos L, Ginarte M, et al: Characterization of TGM1 c.984+1G $>$ A mutation identified in a homozygous carrier of lamellar ichthyosis. Int J Dermatol 2012;51: 427-430.
15 Bourrat E, Blanchet-Bardon C, Derbois C, et al: Specific TGM1 mutation profiles in bathing suit and self-improving collodion ichthyoses: phenotypic and genotypic data from 9 patients with dynamic pPhenotypes of autosomal recessive congenital ichthyosis. Arch Dermatol 2012;148:1191-1195.

16 Boeshans KM, Mueser TC, Ahvazi B: A threedimensional model of the human transglutaminase 1: insights into the understanding of lamellar ichthyosis. J Mol Model 2007;13: 233-246.

17 Sawardekar KP: Prevalence of isolated minor congenital anomalies in a regional hospital in Oman. Saudi Med J 2005;26:1567-1572.

18 Fischer J, Faure A, Bouadjar B, et al: Two new loci for autosomal recessive ichthyosis on chromosomes 3p21 and 19p12-q12 and evidence for further genetic heterogeneity. Am J Hum Genet 2000;66:904-913.

19 Hennies HC, Küster W, Wiebe V, et al: Genotype/phenotype correlation in autosomal recessive lamellar ichthyosis. Am J Hum Genet 1998;62:1052-1061.

20 Lefèvre C, Audebert S, Jobard F, et al: Mutations in the transporter ABCA12 are associated with lamellar ichthyosis type 2 . Hum Mol Genet 2003;12:2369-2378.
21 Mizrachi-Koren M, Shemer S, Morgan M, et al: Homozygosity mapping as a screening tool for the molecular diagnosis of hereditary skin diseases in consanguineous populations. J Am Acad Dermatol 2006;55:393-401.

22 Cserhalmi-Friedman PB, Milstone LM, Christiano AM: Diagnosis of autosomal recessive lamellar ichthyosis with mutations in the TGM1 gene. Br J Dermatol 2001;144:726-730.

23 Raghunath M, Hennies HC, Ahvazi B, et al: Self-healing collodion baby: a dynamic phenotype explained by a particular transglutaminase-1 mutation. J Invest Dermatol 2003; 120:224-228

24 Mazereeuw-Hautier J, Aufenvenne K, Deraison C, et al: Acral self-healing collodion baby: report of a new clinical phenotype caused by a novel TGM1 mutation. Br J Dermatol 2009; 161:456-463.

25 Laiho E, Ignatius J, Mikkola H, et al: Transglutaminase 1 mutations in autosomal recessive congenital ichthyosis: private and recurrent mutations in an isolated population. Am J Hum Genet 1997;61:529-538.

26 Rajab A, Patton MA: A study of consanguinity in the Sultanate of Oman. Ann Hum Biol 2000;27:321-326. 